\title{
Study of the Effect of Calcium lon in dark-induced senescence leaves of peony
}

\author{
Yanwei Cheng ${ }^{1, a}$ JiaoJiao Zhang ${ }^{1}$ Hongxia Liu ${ }^{1}$, Jiawei Zhang ${ }^{1}$ Kai Gao ${ }^{2}$ \\ Huanling Zhang ${ }^{3}$ Yanzhao Zhang ${ }^{1}$ Pengcheng $\mathrm{Fu}^{1}$ Han Jianming ${ }^{1, \mathrm{~b}^{*}}$ \\ ${ }^{1}$ Life science College, Luoyang Normal University, Luoyang 471022, China \\ ${ }^{2}$ Peony Institute of Luoyang, , Luoyang 471022, China \\ ${ }^{3}$ Luoyang Academy of Agriculture and Forestry Sciences, Luoyang471023, China \\ aemail: cywztg@qq.com, bemail: 792531425@qq.com \\ ${ }^{*}$ The Corresponding author: Han Jianming
}

Keywords: peony; dark-induced senescence. calcium ion; chlorophyll

Abstract. The effect of calcium ion on peony aging was studied. Different four calcium ion concentrations $(0 \mathrm{mmol} / \mathrm{L}, 100 \mathrm{mmol} / \mathrm{L}, 250 \mathrm{mmol} / \mathrm{L}, 500 \mathrm{mmol} / \mathrm{L})$ was setted. Leaf of the peony Roufurong on same growth period was cultured in vitro, Chlorophyll concentration was measured per four days. The results revealed that calcium ion concentrations at $100 \mathrm{mmol} / \mathrm{L}$ gave the slowest aging speed among four samples, and when calcium ion concentrations was $500 \mathrm{mmol} / \mathrm{L}$, peony was aging fastest.

\section{Introduction}

Calcium, as a large number of elements in plant, which can be combined with calmodulin, playing an important role in signal transduction. Meanwhile, Calcium can be integrated with the negatively charged cell membrane as the divalent cation, playing a role in stabilizing cell membranes. Poovaiah and their coworkers found $0.1-100 \mathrm{mM} \mathrm{CaCl} 2$ can delay aging speed from leaves of corn and the sorrel, which remained chlorophyll at a high level, the performance of the membrane free space decreased membrane permeability decreased, increased hydration balance[15], but high concentrations of calcium plant will produce stress effect, and reduce the flow of the film, intensify peony aging. In order to verify the effect of calcium on the Luoyang Peony aging, $100 \mathrm{mmo} / 1,250 \mathrm{mmol} / \mathrm{l}$ and $500 \mathrm{mmo} / 1$ of $\mathrm{CaCl} 2$ solution were used to culture peony blades in vitro, chlorophyll content was used as the index to study the leaf aging law.

\section{Materials and Methods}

\section{Source material}

April 10, 2015 with the scissors clipping west of Luoyang Normal University Library of Small garden with Roufurong on the same strain of 12 small sticks, cleaned with water in lab.

\section{Reagents and Instruments}

Reagents: $\mathrm{CaCl}$; $95 \%$ ethanol; quartz sand.

Instruments: mortar; $25 \mathrm{ml}$ graduated cylinder; small funnel; filter paper; absorbent paper; lens paper; pipette; spectrophotometer; electronic balance; cuvettes; centrifuge; tube; $500 \mathrm{ml}$ brown reagent bottle.

\section{Test Method}

\section{Materials Handling}

Four peony leaf samples obtained were placed in four brown reagent bottle, four brown vial contain $100 \mathrm{ml}$ of liquid, these liquids are: water, $100 \mathrm{mmol} / \mathrm{l}$ of $\mathrm{CaCl}_{2}$ solution, $250 \mathrm{mmol} / \mathrm{l}$ of $\mathrm{CaCl}_{2}$ solution, 
$500 \mathrm{mmol} / \mathrm{l}$ of $\mathrm{CaCl}_{2}$ solution. Then sampled at day 0,4 days, 8 days, 12 days were measured in each sample chlorophyll content.

\section{Determination of chlorophyll content}

The method of chlorophyll as References[1,9]:

\section{Data Processing}

Using WPS tables and SPSS data processing software for the recording of data processing,use of biometrics in the univariate analysis of variance variation of the mathematical model of the sample content of chlorophyll content and SOD activity with the calcium ion concentration.

\section{Results and analysis}

After four times measured in 12 days, chlorophyll content in four samples were determined as follows: Table 1 The chlorophyll content of Roufurong leaves by treating $\mathbf{C a C l}_{\mathbf{2}}$ during dark-induced senescence

\begin{tabular}{|c|c|c|c|c|}
\hline & A $(0 \mathrm{mmol} / \mathrm{l})$ & B (100mmol) & C $(250 \mathrm{mmol} / \mathrm{l})$ & $\mathrm{D}(500 \mathrm{mmo} / \mathrm{l})$ \\
\hline \multicolumn{5}{|c|}{ The chlorophyll concentration } \\
\hline \multirow{3}{*}{ One day } & 16.531 & 13.7021 & 12.8147 & 15.2339 \\
\hline & 16.1625 & 13.13 .6129 & 12.6129 & 15.3945 \\
\hline & 16.289 & 13.5692 & 12.6921 & 15.0142 \\
\hline \multirow{2}{*}{$\begin{array}{l}\text { Standards } \\
\text { error }\end{array}$} & $16.32751 \pm 0$ & $13.62806 \pm 0.1$ & $12.70655 \pm 0.122$ & \multirow{2}{*}{$15.21253 \pm 0.2197$} \\
\hline & 242 & 329 & 6 & \\
\hline \multirow{3}{*}{4 days } & 16.4981 & 12.6321 & 11.0196 & 14.0179 \\
\hline & 16.5073 & 12.5916 & 11.0831 & 14.0263 \\
\hline & 16.0278 & 12.4982 & 10.8946 & 13.8941 \\
\hline $\begin{array}{l}\text { Standards } \\
\text { error }\end{array}$ & $\begin{array}{l}16.34439 \pm 0 \\
4702\end{array}$ & $\begin{array}{l}12.57397 \pm 0.1 \\
339\end{array}$ & $10.99912 \pm 0.125$ & $13.97943 \pm 0.1238$ \\
\hline \multirow{3}{*}{8 days } & 12.1972 & 10.9865 & 9.9201 & 12.5603 \\
\hline & 11.8236 & 10.7299 & 10.0106 & 12.5213 \\
\hline & 11.8406 & 10.8019 & 9.6549 & 12.4287 \\
\hline $\begin{array}{l}\text { Standards } \\
\text { error }\end{array}$ & $\begin{array}{l}11.9538 \pm 0.3 \\
566\end{array}$ & $846^{10.83943 \pm 0.1}$ & $9.86185 \pm 0.2652$ & $12.50344 \pm 0.1316$ \\
\hline \multirow{3}{*}{12 days } & 11.0384 & 10.8424 & 8.6343 & 11.1209 \\
\hline & 11.1081 & 10.7973 & 8.5712 & 11.2133 \\
\hline & 10.8527 & 10.658 & 8.471 & 10.9832 \\
\hline $\begin{array}{l}\text { Standards } \\
\text { error }\end{array}$ & $\begin{array}{l}10.99973 \pm 0 \text {. } \\
1857\end{array}$ & $\begin{array}{l}10.76589 \pm 0.1 \\
844\end{array}$ & $8.55883 \pm 0.1633$ & $11.10581 \pm 0.1377$ \\
\hline
\end{tabular}

The relationship between changes of concentration of calcium ion concentration and chlorophyll content as follows

After data analysis of variance, Table 2 shows the number row after analysis of variance calcium ion concentration and chlorophyll content changes of significantly the relationship, because $\mathrm{P}=0.001$, which was lower than 0.05 . The results showed that calcium concentration of tree peony leaves senescence rate was significant relationship, that chlorophyll content and calcium ion concentration. 
Table 2 The test of calcium ions and peony leaf chlorophyll content of the relationship.

\begin{tabular}{|c|l|l|l|l|l|}
\hline Source & $\begin{array}{l}\text { Type Sum } \\
\text { Of Squares }\end{array}$ & df & $\begin{array}{c}\text { Mean } \\
\text { Square }\end{array}$ & F & Sig. \\
\hline Corrected & $69.757 \mathrm{a}$ & 6 & 11.626 & 19.469 & .000 \\
Model & 2459.177 & 1 & 2459.177 & 4118.032 & .000 \\
Intercept & 43.351 & 3 & 14.450 & 24.198 & .000 \\
Days & 26.406 & 3 & 8.802 & 14.739 & .001 \\
Serial & 5.375 & 9 & .597 & & \\
number & 2534.308 & 16 & & & \\
Error & 75.131 & 15 & & & \\
Total & & & & & \\
Corrected & & & & & \\
Total & & & & & \\
\hline
\end{tabular}

a.R Squared=.928(Adjusted R Squared $=.881$ )

In Table 3. numbers represent of each sample, subset not in the same representation column there were significant difference from the data analysis results: A sample (0mmol/ l) and D (500mmol / l) like chlorophyll concentration change of calcium ion concentration relation was not significant, That is becanse the relationship between water and leaf senescence maximum calcium concentration was not significant. And the remaining samples of the rate of aging peony significant differences, that different calcium concentration of tree peony aging at different speeds, no significant relationship between the A sample and the sample D, there are two possible scenarios: First, water and a high calcium the concentration of the same make peony rate of aging, from water to $100 \mathrm{mmol} / 1$ lower leaf senescence rate, higher than after $100 \mathrm{mmol} / 1$ leaf senescence rate increased; Second, there is the experimental error of the A sample and the sample D was not significant one reason.

Table 3 Multiple comparisons of each sample

\begin{tabular}{|c|c|c|c|c|c|}
\hline \multirow{2}{*}{\multicolumn{2}{|c|}{ Serial number }} & \multirow[b]{2}{*}{$\mathrm{N}$} & \multicolumn{3}{|l|}{ Subset } \\
\hline & & & 1 & 2 & 3 \\
\hline \multirow{2}{*}{\multicolumn{2}{|c|}{$\begin{array}{l}\text { Student-Newman-Keuls }{ }^{\mathrm{a}, \mathrm{b}} \\
3.00\end{array}$}} & 4 & 10.5316 & \multirow{4}{*}{11.9518} & \\
\hline & & 4 & & & \\
\hline 2.00 & 4.00 & 4 & & & 13.2003 \\
\hline \multirow[t]{2}{*}{1.00} & \multirow[t]{2}{*}{ Sig } & 4 & & & 13.9064 \\
\hline & & & 1.000 & 1.000 & .229 \\
\hline
\end{tabular}

Means for groups in homogeneous subsets are displayed. Based on Type Sum of Squares The error term is Mean Square(Error)=0.597. a. Uses Harmonic Mean Sample Size $=4.000$ b. Alpha=0.5.

The study has proven that content change of calcium ion concentration and chlorophyll concerned had a different impact on different calcium concentration peony leaf senescence rate, Fig, 1 shows that as the calcium ion concentration increased, chlorophyll was degradatived more faster, when the calcium ion concentration was $100 \mathrm{mmol} / \mathrm{l}$, chlorophyll degradation more least, while the calcium ion concentration was $500 \mathrm{mmol} / 1$, chlorophyll degradation more faster. A sample group of degradation appear abnormal change phenomena, which may be measured according to laboratory fluorescent light emitted decomposition of chlorophyll. 


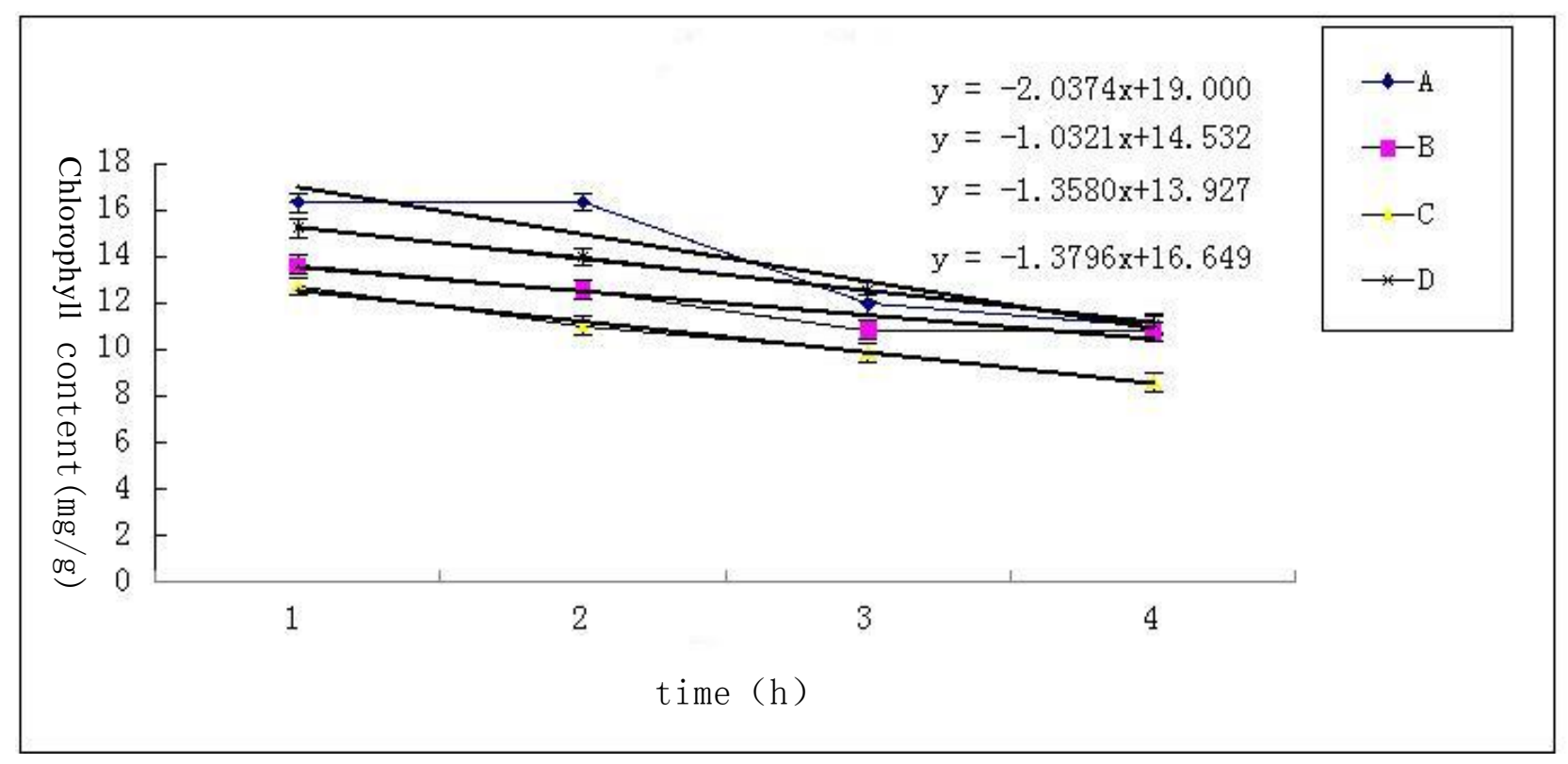

Fig. 1 Changes chlorophyll content of each sample Line charts and trend lines A: water, B: $100 \mathrm{mmol} / 1$ of $\mathrm{CaCl}_{2}, \mathrm{C}: 250 \mathrm{mmol} / 1 \mathrm{CaCl}_{2}$, D: $500 \mathrm{mmol} / 1 \mathrm{CaCl}_{2}$

\section{Discussion}

The experimental result showed that: Calcium not only affects the speed of aging peony, but also different calcium concentration have different effects on the aging rate for the peony. The optimal concentration of calcium ion is $100 \mathrm{mmol} / \mathrm{L}$ during leaf senescence slowest, the result was according with Li Donglin, et al ${ }^{[10-15]}$.

Because the test sample is too small capacity, lack of repetition, limited experimental conditions, is not enough to fully and accurately the impact of calcium on senescence of peony, still need further study in the future by increasing the sample volume, increase the number of repetitions and increase the measurement frequency.

\section{Acknowledgement}

This work was supported by the NSFC(31400602), the NSFC -Henan province joint foundation (U1204307), and the Science and Technology Key Projects of Henan Province (142102110173, 152102210334), the cultivation fundation supported by Luoyang Normal University(2013-PYJJ-001),

\section{References}

[1] Liu Caiyun extraction method, comparative analysis of different reagent extraction of chlorophyll in higher plants Weifang University, 2014,14 (2); 74-76

[2] Xu Xinjuan, Li Yongchao,Zhang Yhangpan etc. Comparison of two methods of extraction of chlorophyll Agricultural Sciences, 2013,52 (21);. 5303-5304

[3] Wang Lan, Fu Sujing, Long Meizhen experimental methods on chlorophyll extract improved test weekly, 2013, (70); 152-153

[4] Zhai Min, Zhang Yan, Feng Zhimin Potted and chlorophyll and antioxidant enzyme activity Metabolism peony leaves Xinyang Agricultural College, 2012,22 (4); 114-116

[5] Li Zhidan, Hanreihong red comparative study of plant chlorophyll extraction of Guangdong Second Normal University, 2011,31 (3);. 80-83 
[6]Zhang Xiujun, Sun Qianqian,Qiao Shuang comparative study spinach chlorophyll extraction crop magazine, 2011, (3); 57-60

[7] Meng Qingting chlorophyll extraction and stability of Hebei Chemical Research, 2009, 32 (3); 2-3

[8] Zhou Mei, Zhao Yan compare three different types of chlorophyll fluorescence characteristics of aging peony leaves Shandong Agricultural Sciences, 2008, (3); 43-47

[9] Yu Xiangli.Peony chlorophyll phase extraction and characterization of Luoyang Normal University, 2005,24 (5);. 107-109

[10] Lifeng Zhao Haoshan Zhang Bingjing Zhang Xiaojuan Bai Chunjiang Zhou.Physiological and Molecular Changes of Detached Wheat Leaves in Responding to Various Treatments.Botany: English, 2012,54 (8); 567-576

[11] Peng ShaoFeng, Wang Zhanying calcium keeping Effect of Cut Peony Northern Horticulture, 2011, (1); 183-184

[12] Zhang Zhe research progress, the role of calcium in plant cells of Anhui Agricultural Sciences, 2011,39 (24);. 14525-14527

[13] Gong Wei calcium in plant abiotic stress resistance in the role of chemistry of life, 2011,31 (1);. 107-111

[14] Ma Chen, Yi Yin, the role of calcium in plant physiological regulation of Guizhou Agricultural Sciences, 2010, (2);. 36-41

[15] Zhang ShengWang, Zheng Guosheng, Meng Li.Effect of calcium content on senescence of cultivated tree peony.Plant Nutrition and Fertilizer Science, 2002,8 (4); 483-487

[16] Zhang Shengwang, Zheng Rongsheng peony flower senescence process of physiological and biochemical changes of Shandong Agricultural University: Natural Science Edition, 2002,33 (2); 166-169

[17] Wang Ruiyun, Wang Yuguo role in plant physiology calcium metabolism [J] World Agriculture, 2001,06: 41-43

[18] Hu Dewen,He ZhiChang, Shi Hongmei physiological regulation of calcium / calmodulin-dependent protein kinase in plants [J] Wuhan Botanical Research, 1999, S1: 89-98 